\title{
FORECASTING ENERGY CONSUMPTION IN SHORT-TERM AND LONG-TERM PERIOD BY USING ARIMAX MODEL IN THE CONSTRUCTION AND MATERIALS SECTOR IN THAILAND
}

\author{
Pruethsan Sutthichaimethee ${ }^{1}$, Danupon Ariyasajjakorn ${ }^{1}$ \\ 1 Faculty of Economics, Chulalongkorn University, Wang Mai, Khet Pathum Wan, Krung Thep Maha Nakhon, \\ Bangkok, Thailand, e-mail: pruethsan@gmail.com, Danupon.A@Chula.ac.th
}

Received: 2017.03 .26

Accepted: 2017.06.04

Published: 2017.07.01

\begin{abstract}
This study aims to analyze the forecasting of energy consumption in the Construction and Materials sectors. The scope of the study covers the forecasting periods of energy consumption for the next 10 years, 2017-2026, 20 years, 2017-2036, and 30 years, 2017-2046, by using ARIMAX Model. The prediction results show that these models are effective in the forecast measured by RMSE, MAE, and MAPE. The results show that from the first model $(2,1,1)$, which predicted the duration of 10 years, 2017-2026, indicates that Thailand has increased an energy consumption rate with the average of $18.09 \%$, while the second model $(2,1,2)$ with the prediction of 20 years, 2017-2036, Thailand arises its energy consumption up to $37.32 \%$. In addition, the third model $(2,1,3)$ predicted the duration of 30 years from 2017 to 2046 , and it has found that Thailand increases its energy consumption up to $49.72 \%$.
\end{abstract}

Keywords: construction and materials sector, population growth, energy consumption, GDP per capita

\section{INTRODUCTION}

Thailand has continued to grow economically after the crisis from 1997 to 2016. In fact, Gross Domestic Product or GDP has an average growth rate of $5.5 \%$ per year [Asian Development Bank (ADB) 2014], while the amount of energy consumption is increasing continuously, especially in the construction sector with the rate of change is as high as 41.43 percent in 2016 compared to 1997. In addition, other economic sectors have continually changed, like manufacturing sectors, transportation sectors, and agricultural sectors, and they are increased by $20.07 \%, 22.96 \%$, $20.07 \%$, and $15.78 \%$, respectively, as shown in Figure 1 [Office of the National Economic and Social Development Board (NESDB) 2015, Thailand Development Research Institute (TDRI) 2007]. However, the energy consumption is the most important driving force in the rapid economic growth [Lee and Tong 2012, Sutthichaimethee and Ariyasajjakorn 2017, Sutthichaimethee and
Sawangdee 2016]. With the needs of setting up short-term and long-term plans, Thailand can become a major new industrialized country in the world. Thus, this phenomenon can create changes in the economy, social and environment [ADB 2014, Sutthichaimethee 2016, Sutthichaimethee and Yotin 2016]. This is to say the economy is continuously growing, while societies become a better place for people in the country; the societies are more towards civilization. Contrarily, this may worsen an environmental condition too [TDRI 2007, Sutthichaimethee 2015, Sutthichaimethee and Sawangdee 2016), Sutthichaimethee et.al 2015].

Hence, the major problem Thailand is currently encountering is that there are no clear short-term and long-term plans and policies for the energy conservation and environmental protection [Sutthichaimethee and Tanoamchard 2015, Zhao and Magoulès 2012]. In fact, the previous plans were anticipated and predicted by an efficient model with unclear concept or the meth- 


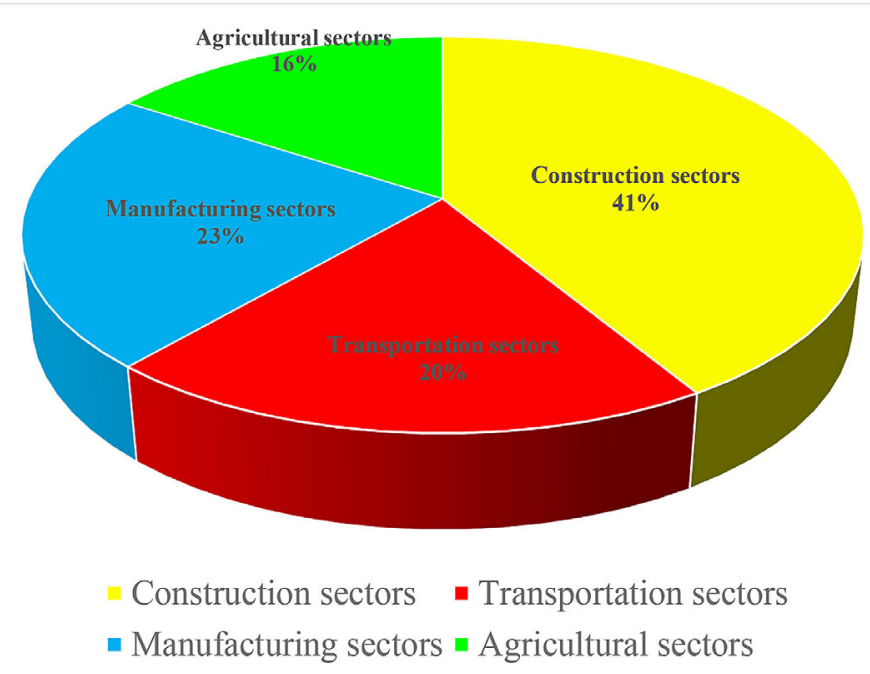

Figure 1. Percentage of change in energy consumption of each sector in Thailand

od used was incomplete [Sutthichaimethee and Yotin 2016, Dong et al. 2005, Sutthichaimethee and Sawangdee 2016]. This results in the wrong determination and establishment of policies (spurious policies), such as regression model is used for forecasting. In addition, various simple models are used because of their convenient use and less time-consuming. For all these reasons, they may result the previous studies and research astray, less effective or even poor in qualities [Chienwattanasook and Sutthichaimethee 2012]. To this research, various theories have been applied, and the method has been accurately and effectively developed as to obtain the best model for such forecasting with less errors compared to other forecasting methods [Yu et al. 2012, Xie et al. 2015, Suganthi and Samuel 2015].

\section{MODEL AND METHODOLOGY}

\section{ARIMAX Model}

The model ARIMAX consists of four parts, namely Auto Regressive (AR), Integrated (I), Moving Average (MA), and Exogenous Variable. The model has the following details.

1. Auto Regressive (AR). The general characteristics of Auto Regressive of order $p$ are as follows:

$$
\begin{aligned}
& Y_{t}=\alpha+\beta_{1} Y_{t-1}+\beta_{2} Y_{t-2}+ \\
& +\ldots+\beta_{p} Y_{t-p}+\varepsilon_{t}
\end{aligned}
$$

where: $\beta_{1} \ldots \beta_{2}$ are parameters, $\alpha$ is a content, and $\varepsilon_{t}$ is the random variable (white noise).

2. Integrated (I) means finding the Difference of variables. It is necessary to find the difference, because the ARIMA is non stationary, so it must be converted in to be stationary by difference in $\mathrm{p}$ order.

3. Moving Average (MA) is bringing the error term from forecasting to calculate from the difference between variables that really happen (Y Actual)with the dependent variables (Y Forecast) or $\varepsilon_{t}=Y_{a t}-Y_{f t}$ in the past to help with forecasting the variables needed in the future as the following form:

$$
\begin{aligned}
& Y_{t}=\delta+\boldsymbol{E}_{t}-\gamma_{1} \boldsymbol{E}_{t-1}+ \\
& -\gamma_{2} \boldsymbol{\varepsilon}_{t-2}-\ldots-\gamma_{q} \boldsymbol{E}_{t-q}
\end{aligned}
$$

where: Moving Average of Order q or MA(q) by q means last order of error value used.

The form of model development ARIMA is ARIMA (p,d,q). That is Order of $A R=p$ of $I=d$ and of $M A=q$ respectively.

ARIMAX model is the model adapted from ARIMA Model. The reason is that when designate tdependent variable to be energy consumption $(\mathrm{t})$ and independent variable are various, such as energy consumption (t-i), population and GDP growth. Therefore, in order to be accurate model and good result of forecast of energy consumption in the future, the researcher chose to use the 
ARIMAX Model [Sutthichaimethee and Ariyasajjakorn 2017] which has the following details.

\section{Steps for making the modeling and forecasting are as follow:}

1. Bring the data used in the study to analyze for Stationary by testing the Unit Root from the concept of Augment Dickey and Fuller

Stationary: Stationary Stochastic Process as known in short as Stationary is the series of time data with mean or expected value, variance, constant overtime, and covariance. It does not depend on time, but on distance or lag. Given $\mathrm{Y}_{t}$ as the Stochastic Time Series and has Stationary, there must be three properties as follows:

Mean:

$$
E Y_{t}=E Y_{t+k}=\mu
$$

Variance: $\operatorname{VAR}\left(Y_{t}\right)=E\left(Y_{t-\mu}\right)^{2}=\sigma^{2}$

Covariance: $\quad E\left(Y_{t-\mu}\right)\left(Y_{t+k-\mu}\right)=\gamma_{k}$

From the equation (3), (4), and (5), it can be found that $\gamma_{k}$ is covariance between $Y_{t}-Y_{t+k}$, which has the distance between two values of $Y$, but it does not depend on time. It can be seen in the case of random variables be stationary stochastic process. Probability distribution will not change in each time. It is the expected value and constant variance in case of $\varepsilon_{\mathrm{t}}$ lacks property of being White Noise. That is it has the property of autocorrelation, which is having the high correlations or higher order autoregressive process. Therefore, a test in the form of Augmented Dickey Fuller (ADF) is needed. The form of equation has added the lagged variables in the higher level to eliminate the Autocorrelation, Heterosckasticity, and Multicollinearity as follows:

$$
\begin{gathered}
\Delta Y_{t}=\delta_{1} Y_{t}+\sum_{i=2}^{p} \beta_{i} \Delta Y_{t-i+1}+\varepsilon_{t} \\
\Delta Y_{t}=\alpha_{1}+\delta Y_{t-1}+ \\
+\sum_{i=2}^{p} \beta_{i} \Delta Y_{t-i+1}+\varepsilon_{t} \\
\Delta Y_{t}=\alpha_{1}+\alpha_{2} T+\delta Y_{t-1}+ \\
+\sum_{i=2}^{p} \beta_{i} \Delta Y_{t-i+1}+\varepsilon_{t}
\end{gathered}
$$

From the mentioned equations, the value of $p$ was sent to be the lagged values of first difference of the variable by testing the Unit Root with the Augmented Dickey Fuller method as follows:

$$
\begin{aligned}
& \Delta Y_{t}=\alpha_{1}+\alpha_{2} T+\delta Y_{t-1}+ \\
& +\sum_{i=2}^{p} \beta_{i} \Delta Y_{t-i+1}+\varepsilon_{t}
\end{aligned}
$$

From the equation above, three problems were taken into account, especially the autocorrelation in $\varepsilon$ t was set to have the property of White Noise which is the Error Term has the mean of 0 and constant under the following hypotheses:

$$
\begin{aligned}
& \mathrm{H} 0: \delta=0, \text { Non-Stationary } \\
& \mathrm{H} 1: \delta<0 \text {, Non-Stationary }
\end{aligned}
$$

If tau-statistics of the efficiency $\delta$ are in the form of absolute term, it must be more that critical values appearing in the ADF table. That is failing to retain the major hypothesis. This means that the time series of variables are stationary so it can be stated that $\Delta \mathrm{Y}_{\mathrm{t}}$ Integrated Number $\mathrm{d}$ representing by $\Delta \mathrm{Yt} \sim \mathrm{I}(\mathrm{d})$.

2. Bring the data that are stationary at the same level only both for the dependent variables and independent variables (at level of $1^{\text {st }}$ moment and/or $2^{\text {nd }}$ moment only) to analyze the longterm relationship or finding co-integration in which if variables in the model correlate each other in the long term in the same level, it shows that in that model, vector error-correction model (ECM) must be found in order to create the best model next.

For this research, Co-integrated Relationships was obtained with the Full Information Maximum Likelihood (FIML) Approach as presented by Johansen and Juselius (1990) because 1) the model can be applied to use with two variables or more, 2) Number of Co-integrating Vector can be tested altogether without having to specify the variables as to which is exogenous variable and endogenous variable.

For the approach of Johansen and Juselius, it is the test method in the form of Multivariate Cointegration by referring to the model called vector autoregressive (VAR) Model.

$$
\begin{aligned}
& \Delta X_{t}=\mu+\sum_{i=1}^{k-1} \Gamma_{i} \Delta X_{t}, \Delta X_{t-1}+ \\
& -\Pi X_{t-k}+u_{t}
\end{aligned}
$$


From the approach of Johansen and Juselius, test must be conducted to find Co-integrating Vectors of variables $X_{t}$ in VAR Model. It is necessary to find the most suitable Lag to verify VAR Model. It is popularly done by considering the Likelihood Ratio Test of Sims (1980) or the approach of Minimum Final Prediction Error Test Akaike which has the following steps.

Step 1. Set the equation needed testing which is based on Vector Autoregressive Model (VAR), for example,

$$
\Delta X_{t}=\sum_{i=1}^{k-1} \Pi_{i} \Delta X_{t-i}+\Pi X_{t-k}+u_{t}
$$

Step 2. Test to find the number of Lag that is suitable for the set equation.

Step 3. Co-integrating Vectors between variables in the model and find the rank of metric $\pi$ which is equal to Rows or Columns that is independent of $\pi$

Step 4. Use two types of statistical tests to find the number of Co-integrating Vectors (r) inside the model such as Trace Test and Maximum Eigenvalue Test. The testing of both often go together in order to check for accuracy

3. Estimate the model to create the Best Model. That is independent variable must show true influence on dependent variables. The impacts are considered from the value of tau-statistics which must have significance of difference at the level of $5 \%, 10 \%$, and $15 \%$.

4. Bring the created Best Model to test for problems of three types. The first is Autocorrelation

\subsection{Testing for Autocorrelation by using Lagrang- ian Multiplier Test - LM test}

LM Test is used in case the equation has lagged variables of the dependent variables appear to be independent variables. It cannot be tested with Durbin-Watson. Besides, the LM can be used to test in case Error Terms have autocorrelation problem in high level. The following is the testing methods.

$$
\begin{aligned}
& Y_{t}=\alpha_{0}+\alpha_{1} X_{t}+\beta_{1} U_{t-1}+ \\
& +\beta_{2} U_{t-2}+\ldots+\beta_{p} U_{t-p}
\end{aligned}
$$

Calculate the equation $Y_{t}=\alpha_{1} X_{t} \ldots+U_{t}$ to get Residual. By having the major hypothesis $\mathrm{H} 1: \beta 1=\beta 2=\ldots=\beta p=0$ and the statistical test is $n R^{2} \approx \chi^{2} p$ andF-Test $=\frac{n-k}{m} \times \frac{R^{2}}{\left(1-R^{2}\right)}$

If $\chi^{2} p$ and $F_{m, n-k}$ - Test Statistic is more that the value Critical $\chi^{2}$ and value of $\mathrm{F}$ Critical is at the chosen level of significance, the major hypothesis is failed to retain. That is at least one $\beta$ has the value difference from 0 . This means that there is Autocorrelation problem.

\subsection{Testing the Heteroskedasticity by using ARCH Test}

ARCH Testing is used to test Heteroskedasticity in Time series. When the Residual is obtained, it is calculated with the lagged variables of the residual by considering the value of $\mathrm{F}$ and $n R^{2}$ which has Chi-Square distribution. If the $\chi^{2} p$ statistical test has higher value that the critical value of $\chi^{2} p$ from the table of chosen significance level, the hypothesis is failed to be retain because it seems to have Heteroskedasticity.

4.3. Testing the Multicorrelinearityby using correlation test and to test for response from the value of Correlogram compared to chisquare value.

5. Check for the accuracy of forecasting for the purpose of evaluating the out of sample forecast capability, the forecasting accuracy is examined by calculating thee different evaluation statistics: the root mean square error (RMSE), the mean absolute (MAE), and the mean absolute percentage error (MAPE). For this research, the model that has MAPE value less than $30 \%$ is selected in order to find the result with the least error [Pruethsan and Danupon 2017, Pappas et al. 2008].

\section{RESULTS AND DISCUSSION}

The results of the forecasting model of the Energy consumption (EC), Population growth (Population), and GDP per capitaare (GDP) classified by each category of the production. This research can be summarized as follows:

1. Unit Root Test: with the Augmented DickeyFuller test is shown in Table 1 as below;

The ADF Test Statistic at level of all variables has a variable unit root component or Non Stationary i.e. the value calculated from the ADF, are all lower than the critical value. From the table at 
Table 1. Unit Root test at level

\begin{tabular}{|c|c|c|c|c|c|c|}
\hline \multirow{2}{*}{ Variables } & \multirow{2}{*}{ Lag } & \multirow{2}{*}{ ADF Test } & \multicolumn{3}{|c|}{ MacKinnon Critical Value } & \multirow{2}{*}{ Status } \\
\cline { 4 - 6 } & & & $1 \%$ & $5 \%$ & $10 \%$ & \\
\hline $\ln (E C)$ & 1 & -2.14 & -4.12 & -3.27 & -3.05 & $\mathrm{I}(0)$ \\
\hline $\ln ($ Population $)$ & 1 & -2.98 & -4.12 & -3.27 & -3.05 & $\mathrm{I}(0)$ \\
\hline $\ln (G D P)$ & 1 & -3.03 & -4.12 & -3.27 & -3.05 & $\mathrm{I}(0)$ \\
\hline
\end{tabular}

the significance level of $1 \%, 5 \%$ and $10 \%$, so that it must be to qualify as Stationary by the difference moment. This research found that all variables Stationary at the first differencing included Energy consumption, Population growth, and GDP per capita. The value of the test based on the "Tau-test" is greater than the all "Tau-critical" at the first difference, results in Table 2.

\section{Result of the Co-integration Test}

The result in Table 2 bring all variables are Stationary at the first difference to test Co-integration by using the method of "Jansen Juselius" shown in Table 3.

As the results, "Co-integration test" showed that model is a Co-integration because of the Trace Test is 270.78 , which is higher than the critical value at significance level of $1 \%$ and $5 \%$, the Maximum Eigen value test at 198.45 which is higher than the critical value significance level of $1 \%$ and $5 \%$.

3. The result of ARIMAX Model

1) ARIMAX Model $1(2,1,1)$

$\Delta \ln (E C)_{\mathrm{t}}=-0.31+3.46 \Delta \ln (E C)^{* *}{ }_{\mathrm{t}-1}+$

$+3.14 \Delta \ln (E C)^{* *}{ }_{\mathrm{t}-2}+5.78 \Delta \ln$ Population $^{* *}{ }_{\mathrm{t}-1}+$

$+6.15 \Delta \ln (G D P)^{* *}{ }_{\mathrm{t}-1}+2.77 M A^{* *}{ }_{1}+2.78 E C M^{* *}$

where ${ }^{* *}$ is significance $\alpha=0.01,{ }^{*}$ is

significance $\alpha=0.05$, R-squared is 0.96 ,
Adjusted R-squared is 0.94, Durbin-Watson stat is 2.25, F-statistic is 241.05 (Probability is 0.00 ), ARCH-test is 30.75 (Probability is 0.1 ), LM - test is 1.65 (Probability is 0.10$)$ and response test $\left(\chi^{2}>\right.$ critical $)$ is significance.

2) ARIMAX Model $1(2,1,2)$ $\Delta \ln (E C)_{\mathrm{t}}=-0.32+3.05 \Delta \ln \left(C O_{2}\right) *{ }_{\mathrm{t}-1}+$ $3.98 \Delta \ln \left(\mathrm{CO}_{2}\right) *{ }_{\mathrm{t}-2}+5.69 \Delta \ln$ Population $^{* *}{ }_{\mathrm{t}-1}$ $+2.71 \Delta \ln (G D P)^{* *}{ }_{\mathrm{t}-1}+2.03 M A^{*}{ }_{1}+$

$+2.16 M A^{*}{ }_{2}+3.48 E C M^{* *}$

where $* *$ is significance $\alpha=0.01, *$ is significance $\alpha=0.05$, R-squared is 0.94 , Adjusted R-squared is 0.93, Durbin-Watson stat is 2.29, F-statistic is 210.15 (Probability is 0.00 ), ARCH-test is 25.78 (Probability is 0.10 ), LM - test is 1.80 (Probability is 0.15$)$ and response test $\left(\chi^{2}>\right.$ critical) is significance.

3) ARIMAX Model $1(2,1,3)$

$\Delta \ln \left(C O_{2}\right)_{\mathrm{t}}=-0.59+3.75 \Delta \ln \left(C O_{2}\right)^{* *}{ }_{\mathrm{t}-1}+$

$+3.91 \Delta \ln \left(\mathrm{CO}_{2}\right)^{* *} \mathrm{t}_{\mathrm{t}-2}+4.69 \Delta \ln$ Population $^{* *}{ }_{\mathrm{t}-1}$

$+5.66 \Delta \ln (G D P)^{* *}{ }_{\mathrm{t}-1}+1.79 M A^{*}{ }_{1}+2.21 M A^{*}{ }_{2}$

$+2.01 \mathrm{MA}_{3}{ }_{3}+2.63 E C M^{* *}$

where ${ }^{* *}$ is significance $a=0.01,{ }^{*}$ is significance $\alpha=0.05$, R-squared is 0.87 , Ad-

Table 2. Unit Root test at the first difference

\begin{tabular}{|c|c|c|c|c|c|c|}
\hline \multirow{2}{*}{ Variables } & \multirow{2}{*}{ Lag } & \multirow{2}{*}{ ADF Test } & \multicolumn{3}{|c|}{ MacKinnon Critical Value } & \multirow{2}{*}{ Status } \\
\cline { 4 - 7 } & & & $1 \%$ & $5 \%$ & $10 \%$ & \\
\hline $\ln (E C)$ & 1 & -4.79 & -4.22 & -3.36 & -3.25 & $\mathrm{I}(1)$ \\
\hline $\ln ($ Population $)$ & 1 & -6.02 & -4.22 & -3.36 & -3.25 & $\mathrm{I}(1)$ \\
\hline $\ln ($ GDP $)$ & 1 & -5.12 & -4.22 & -3.36 & -3.25 & $\mathrm{I}(1)$ \\
\hline
\end{tabular}

Table 3. Co-integration test by Johansen Juselius

\begin{tabular}{|c|c|c|c|c|c|c|c|c|}
\hline \multirow{2}{*}{ Variables } & \multirow{2}{*}{$\begin{array}{l}\text { Hypothesized } \\
\text { No. of CE(S) }\end{array}$} & \multirow{2}{*}{$\begin{array}{c}\text { Trace } \\
\text { Statistic Test }\end{array}$} & \multicolumn{2}{|c|}{$\begin{array}{c}\text { MacKinnon Critical } \\
\text { Value }\end{array}$} & \multirow{2}{*}{$\begin{array}{l}\text { Max-Eigen } \\
\text { Statistic Test }\end{array}$} & \multicolumn{2}{|c|}{$\begin{array}{c}\text { MacKinnon Critical } \\
\text { Value }\end{array}$} & \multirow{2}{*}{ Status } \\
\hline & & & $1 \%$ & $5 \%$ & & $1 \%$ & $5 \%$ & \\
\hline \multirow{2}{*}{$\begin{array}{c}\Delta \ln (E C) \\
\Delta \ln (\text { Population } \\
\Delta \ln (G D P))\end{array}$} & None ${ }^{* \star}$ & 270.78 & 19.75 & 15.41 & 198.45 & 15.68 & 14.07 & $\mathrm{I}(1)$ \\
\hline & At Most $1^{* *}$ & 70.75 & 5.75 & 3.16 & 70.75 & 5.75 & 3.16 & $\mathrm{I}(1)$ \\
\hline
\end{tabular}


justed R-squared is 0.85, Durbin-Watson stat is 2.35, F-statistic is 111.02 (Probability is 0.00 ), ARCH-test is 25.24 (Probability is 0.10 ), LM - test is 1.04 (Probability is 0.19$)$ and response test $\left(\chi^{2}>\right.$ critical) is significance.

4. The results of forecasting model

When the modeling ARIMAX Model $1(2,1,1)$, ARIMAX Model $2(2,1,2)$, and ARIMAX Model $3(2,1,3)$ which is the best model that was used to predict 3 models. The first, 10 years forecast (2017-2026), the second, 20 years forecast (2017-2036) and the third, 30 years (2017-2046) the forecast results shown in Figures 2,3 , and 4 .

The results forecasts found that the model 1 (2017-2026) energy consumption volume increased steadily and average rising up to $18.09 \%$ in 2026, the model 2 (2017-2036) energy consumption volume increased steadily as well and average rising to $37.32 \%$ in 2036 and the model 3 (2017-2046) energy consumption volume increased steadily as well and average rising to $49.72 \%$ in 2046 . However, that model 1 , model 2 , and model 3 were tested the effectiveness of the model compared with actual value found that both models are highly effective with the low deviation can be used to decision making that shown in MAPE equal to $1.01,1.11$, and 1.78 , respectively, (less than 3\%) and test results showed that correlogram, the modeling value, can be used as the best model for predicting and forecasting the lowest tolerances value.

After reviewing the literatures from many sources, such as Jain (2010) applied Gray-Markov model, Grey-model with rolling mechanism, and singular spectrum analysis (SSA) used to forecast the consumption of conventional energy in India, while Dong et al. (2005) and Ekonomou (2010) used an ANN model to predict the energy consumption, and Weijun Xu et al. (2015) established a

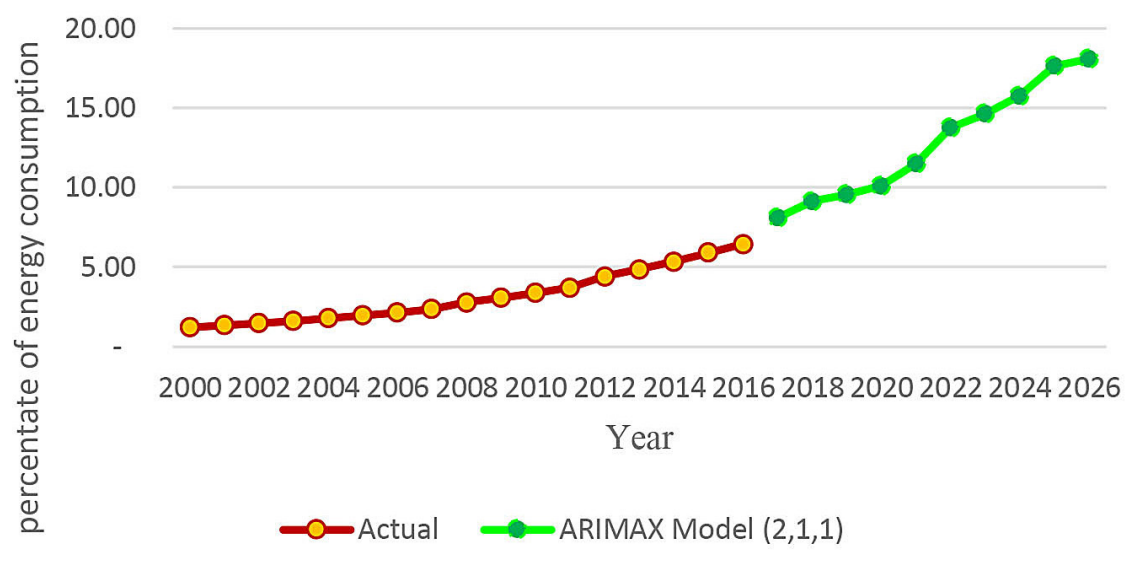

Figure 2. Forecasting from ARIMAX Model $1(2,1,1)$

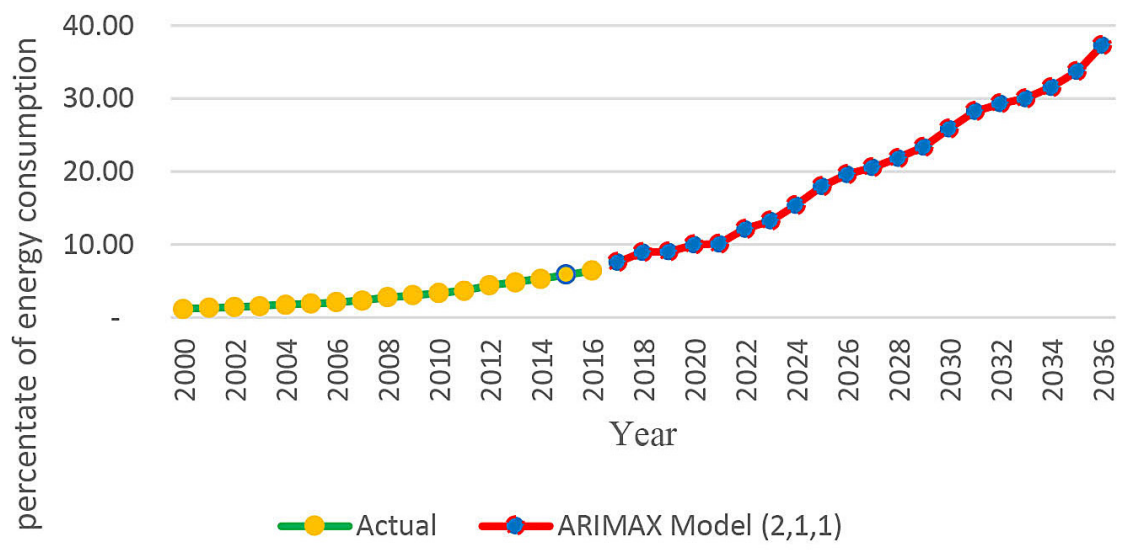

Figure 3. Forecasting from ARIMAX Model $2(2,1,2)$ 


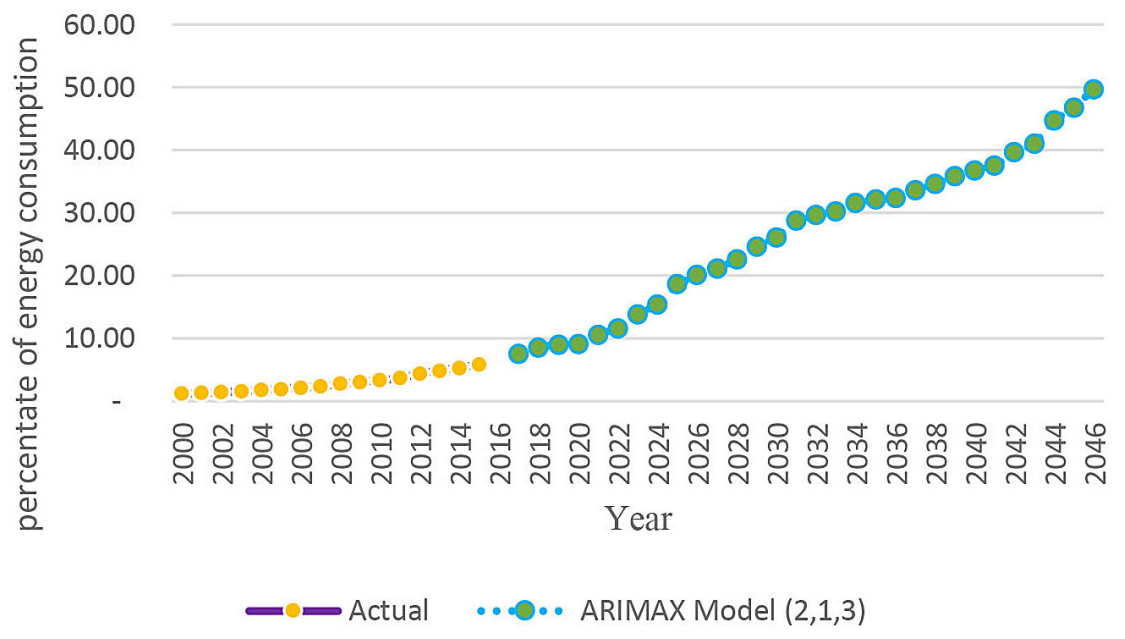

Figure 4. Forecasting from ARIMAX Model $3(2,1,3)$

new model with the improved GM-ARIMA based on HP Filter to forecast the final energy consumption of Guangdong Province in China and etc, they are all basically aimed to forecast the energy consumption in certain areas with their developed and improved forecasting model and methodology.

\section{CONCLUSION}

From the study with the use of ARIMAX Model, it has found that model 1 with the forecasting period of 10 years, 2017-2026, gives the rate of energy consumption increased by $18.09 \%$, while model 2, forecasted in the year of 2017 until 2036, indicates an increase in the energy consumption rate of $37.32 \%$, and model 3, predicted within the period of 2017 until 2046 deemed to increase $49.72 \%$. The outcomes from this study can be seemingly incorporated into both shortterm and long-term national policies planning. Plus, the researcher has verified the accuracy of the actual data (Actual Data) and the quality of MAPE, and RMFE models. Moreover, any vulnerable element towards spurious, such as Autocorrelation, Heteroskedasticity, and Multocollinearity, has also been eliminated. To Thailand, it is necessary to apply the study's model, that has been developed to achieve the maximum benefit. It should also be used for planning and decision-making to determine the country's policies in both short-term and long-term period. To achieve a sustainable development of the country, Thailand must ensure and secure these three elements: a growing economy, a better environment, and a better-living society. If any of these is missed out, then the sustainable development will not take place.

\section{Acknowledgements}

This research is supported by Rachadapisek Sompote Fund for Postdoctoral Fellowship, Chulalongkorn University.

\section{REFERENCES}

1. Asian Development Bank (ADB). 2014. Environment, Climate Change, and Disaster Risk Management. Manila. Asian Development Bank.

2. Assaad M., Boné R., Cardot H. 2008. A new boosting algorithm for improved time-series forecasting with recurrent neural networks. Inform Fusion, 9, 41-55.

3. Azadeh A., Asadzadeh S., Saberi M., Nadimi V., Tajvidi A., Sheikalishahi M. 2011. A neuro-fuzzystochastic frontier analysis approach for long-term natural gas consumption forecasting and behavior analysis: the cases of Bahrain, Saudi Arabia, Syria, and UAE. Appl Energy, 88, 3850-9.

4. Azadeh A., Saberi M., Seraj O. 2010. An integrated fuzzy regression algorithm for energy consumption estimation with non-stationary data: a case study of Iran. Energy, 35, 2351-66.

5. Barak S., Dahooie JH., Tichy' T. 2015. Wrapper ANFIS-ICA method to do stock market timing and feature selection on the basis of Japanese Candlestick. Expert Syst Appl, 42, 9221-35.

6. Ciabattoni L., Grisostomi M., Ippoliti G., Longhi S. 2014. Fuzzy logic home energy consumption modeling for residential photovoltaic plant sizing in the new Italian scenario. Energy, 74, 359-67.

7. Chienwattanasook K., Sutthichaimethee P. 2012. 
Trend of Thailand jewelry export to the USA market. International Academy of Business and Economics, 12(3).

8. Dong B., Coa C., Lee S.E. 2005. Applying support vector machines to predict building energy consumption in tropical region. Energy Build, 37, 545-553.

9. Ekonomou L. 2010. Greek long-term energy consumption prediction using artificial neural networks. Energy, 35, 512-517.

10. Hao J., Liu D., Li Z., Chen Z., Kong L. 2012. Power system load forecasting based on fuzzy clustering and gray target theory. Energy Proc, 16, 1852-1859.

11. Jovanovic RZ., Sretenovic AA., Zivkovic BD. 2015. Ensemble of various neural networks for prediction of heating energy consumption. Energy Build, 94, 189-199.

12. Lee Y-S., Tong L-I. 2011. Forecasting energy consumption using a grey model improved by incorporating genetic programming. Energy Convers Manage, 52, 147-152.

13. Lee Y-S., Tong L-I. 2012. Forecasting nonlinear time series of energy consumption using a hybrid dynamic model. Appl Energy, 94, 251-256.

14. Leontief W.W. 1986. Input-Output Economics (2nd ed.). New York, Oxford University Press.

15. Mamlook R., Badran O., Abdulhadi E. 2009. A fuzzy inference model for short-term load forecasting. Energy Policy, 37, 1239-1248.

16. Office of the National Economic and Social Development Board. 2015. National Income of Thailand. Bangkok: NESDB.

17. Osorio G., Matias J., Catalão J. 2015. Short-term wind power forecasting using adaptive neurofuzzy inference system combined with evolutionary particle swarm optimization, wavelet transform and mutual information. Renew Energy, 75, 301-307.

18. Pappas S.S., Ekonomou L., Karamousantas D.C., Chatzarakis G., Katsikas S., Liatsis P. 2008. Electricity demand loads modeling using Auto Regressive Moving Average (ARMA) models. Energy, 33, 1353-1560.

19. Suganthi L., Iniyan S., Samuel AA. 2015. Applications of fuzzy logic in renewable energy systems a review. Renew Sustain Energy Rev, 48, 585-607.

20. Suganthi L., Samuel A.A. 2012. Energy models for demand forecasting - a review. Renew Sustain Energy Rev, 16, 1223-1240.
21. Sutthichaimethee P. 2016. Modeling environmental impact of machinery sectors to promote sustainable development of Thailand. Journal of Ecological Engineering, 17(1), 18-25.

22. Sutthichaimethee P., et al. 2016. Model of environmental problems priority arising from the use of environmental and natural resources in construction material sectors of Thailand. Advanced Engineering Forum, 14, 76-85.

23. Sutthichaimethee P., et al. 2015. Environmental problems indicator under environmental modeling toward sustainable development. Global J. Environ. Sci. Manage., 14(1), 325-332.

24. Sutthichaimethee P., Tanoamchard W. 2015. Carrying capacity model of food manufacturing sectors for sustainable development from using environmental and natural resources of Thailand. Journal of Ecological Engineering, 16(5), 1-8.

25. Sutthichaimethee P., Sawangdee Y. 2016. Model of environmental impact of service sectors to promote sustainable development of Thailand. Ethics Sci Environ Polit, 16(1).

26. Sutthichaimethee P., Sawangdee Y. 2016. Indicator of environmental problems priority arising from the use of environmental and natural resources in machinery sectors of Thailand. Environmental and Climate Technologies .17(1), 18-29.

27. Sutthichaimethee P., Sawangdee Y. 2016. Indicator of environmental problems of agricultural sectors under the environmental modeling. Journal of Ecological Engineering, 17(2), 12-18.

28. Sutthichaimethee P., Ariyasajjakorn D. 2017. Forecasting model of GHG emission in manufacturing sectors of Thailand. Journal of Ecological Engineering, 18(1), 18-24

29. Thailand Development Research Institute (TDRI). 2007. Prioritizing environmental problems with environmental costs. Final report prepared the Thailand Health Fund. Bangkok.

30. Xie N-m., Yuan C-q., Yang Y-j. 2015. Forecasting China's energy demand and self sufficiency rate by grey forecasting model and Markov model. Int $\mathbf{J}$ Electr Power Energy Syst, 66, 1-8.

31. Yu S., Wei Y-M., Wang K. A. 2012. PSO-GA optimal model to estimate primary energy demand of China. Energy Policy, 42, 329-340.

32. Zhao H., Magoulès F. 2012. A review on the prediction of building energy consumption. Renewable Sustainable Energy Rev, 16, 3586-3592. 